\title{
Chinese Yibin Liquor Culture Goes Global ${ }^{*}$
}

\author{
YUAN Xuezhe \\ Sichuan University of Science and Engineer, Yibin, China
}

\begin{abstract}
Chinese national culture is extensive and profound, and liquor culture is an important part of it. As an important part of Chinese liquor culture, Yibin liquor culture in Sichuan Province not only has the weight of Chinese traditional culture, but also has the new characteristics of Sichuan liquor industry under the new normal. Chinese culture of moderation, loyalty and Chinese culture can be found in Yibin liquor brand. Nowadays, Yibin liquor, the capital of liquor, is popular in five continents for its rich aroma and long Chinese culture. It is of great significance to promote the dissemination of "Sichuan liquor" culture that enhances the multilingual communication of "Sichuan liquor" culture and strengthens traditional culture education to increase consumers' recognition of Chinese liquor culture.
\end{abstract}

Keywords: China, Yibin, liquor culture, liquorcity, elegant, wuliangye, international communication

China is one of the three ancient countries of liquor culture in the world, and the only country whose liquor culture has never been interrupted and has been well inherited till now. China has a long history of liquor culture, with more than 6,000 years of history of liquor culture, and is the country with the longest history of liquor culture in the world. (Liu, 2017, p. 26)

Liquor culture is a dynamic organic whole composed of various characteristic consumption groups, producers and operators of alcohol, enjoying different levels of material culture and consciousness culture about liquor from the past to the future in a specific region at a specific time. (Liu, 2017, p. 28)

Chinese Sichuan Yibin liquor culture includes Yibin liquor development history, brand culture and celebrity culture resources. The pan-media era has brought a new way of information dissemination, and the communication system of Sichuan liquor culture is changing. (Liang, 2014, p. 305)

The international communication of Chinese Sichuan Yibin liquor culture, which crosses the national boundaries, helps Sichuan liquor culture to go international and form a global influence.

\section{A History of Yibin Liquor Culture}

Yibin is one of the cradles of Chinese liquor culture and the epitome of Chinese liquor culture. Yibin has a long history of liquor making and has produced famous liquors for thousands of years. The weather here is warm and rainy in the same season, and the air and soil are most suitable for the growth of microorganisms needed for liquor making. The first people to live here, drinking was their special hobby, fermented "lychee liquor", "shitou liquor", later learned to brew artificially, which created the first bo dao liquor culture in south Sichuan.

\footnotetext{
${ }^{*}$ Fund: Sichuan Provincial Department of Education Philosophy and Social Science Key Base Project: Internet + Sichuan Liquor Culture International Communication Strategy Research CJCB2016-06.

Yuan Xuezhe, Doctor, Associate Professor, Institute of Marxism, Sichuan University of Science and Engineer, Yibin, China.
} 
The so-called tree head liquor is to use a unique tree; the tree tip of the juice can naturally give birth to "liquor", called tree head liquor. After this liquor comes the artificially brewed liquor "pepper sauce" and "scenting liquor". "Pepper sauce" is made of beans and "scenting liquor" is made of barley, wheat, glutinous rice, and sorghum. The bo people are good at making scenting liquor. This brewing method is still popular today in Caoying, Gongxian County.

Archaeological experts from Yibin in the Han Dynasty tombs and hoard unearthed a large number of bronze vessels, such as food, pot, spoon; modelling is exquisite, exquisite ornamentation, and a large number of ceramic liquor. Valley temple rock tomb, unearthed a vibrant gu liquor terracotta. On the sarcophagus of the Han Dynasty tomb of Childe Mountain in Yibin County, there is a relief sculpture of "cooking and feasting”. Changning Feiquan east Han Dynasty rock tomb inscribed with "farewell dinner for husband and wife diagram”... This proves that in Yibin of Han Dynasty, liquor has penetrated into every aspect of social life.

When the history entered into the Tang Dynasty, Yibin liquor has become a real name, and there was a prominent liquor at that time, "heavy blue liquor”, respected by all the poets. Du Fu once praised Yibin's "heavy biyan spring liquor" in his famous poems.

In the Song Dynasty, Yibin liquor has reached a considerable scale, according to the Song Dynasty "xining liquor class" calculation, when the Northern Song Rongzhou liquor class is 5,000, the annual output reached 522,500 metric tons, 37,500 stone grain consumption. In the Song Dynasty, Yibin liquor industry developed more rapidly and the liquor culture appeared unprecedented prosperity under the promotion of the great poet Huang tingjian.

600 years ago in the Ming Dynasty, Yibin improves brewing technology, on the magical land of Yibin, a commercial manual mill—bad house, including the famous Windshield and blessing replace, long hair, the worse fang. Yibin wuliangye has been extended since the Ming Dynasty 16 old cellar pool. The 16 mouth ancient cellar pool is the witness of Yibin long liquor-making history. Now the hale and hearty, is still silently with producing good liquor.

On the periodic history of liquor, the emergence of wuliangye is always worth remembering. In $1900 \mathrm{AD}$, The 10th generation of descendants of name Chen inheritanced ancestral "Windshield" liquor workshop in Yibin, on the basis of the original brewing, refined "Chen secret recipe" wuliangye Deng Zijun scored the founder "Chen secret recipe" ancestral secret recipe, using five foods as the raw material of liquor making. Consistency in liquor wuliangye liquor culture, long has now become "China’s liquor king”.

\section{Yibin Liquor Culture Further Sublimation}

Through four thousand years of historical precipitation, in the traditional and modern cycle, today, Yibin liquor culture is to further sublimation.

In Yibin, there are large liquor culture relief carvings everywhere, reappearing the elegant demeanor of Yibin's liquor culture with vivid patterns. Place oneself among them, trance passed through the tunnel of time and space, return to thousand years of history sea, pick up the precious shellfish of years. Whether in Guanying Street, Zhanfang Street, or in the Streets of Gurong State, the flag-waving liquor shows a strong aroma. Seven or eight ferrymen, with their exhaustion and joy of harvest, can be seated on the threshold or table on the floor. As long as there are a few dishes of white meat, a pot of old liquor, they can forget the world, secular.

Yibin becoming "China's liquor" is not only her liquor, also is in one thousand to alcohol hangover perfectly following in Yibin. Yibin family brewed liquor, liquor handed down, formed a unique liquor style. 
The "China liquor” circulated "no liquor no section”, "no liquor no seats”, “no liquor no huan”, "no liquor no blast”, "liquor is feast” rules.

"Singing to liquor" and "asking the sky for liquor" represent a lofty realm. In addition, drinking etiquette has always been a very important part of the traditional Chinese culture. Since ancient times, people have paid attention to the ceremony of paying with tussah, which has been extended to religious sacrifice, which reflects the Chinese culture of humility, comity and gratitude (Zhong \& Yun, 2017, p. 44). The elegant Sichuan liquor culture exerts more positive influence on the public and forms a positive internalization effect.

Sichuan hongloumeng liquor industry, in the operating difficulties, calls for the reorganization of property rights: China railway construction industry from Ping An Trust to take over hongloumeng liquor industry. China railway construction group successfully bid for the creditor's rights package, which explored a feasible path for the creditor's rights and debt treatment of hongloumeng liquor industry, and laid a foundation for the restructuring of hongloumeng liquor industry in the future. Tuopai group will introduce Tianyang group to invest 3.82 billion yuan, becoming the first successful case of mixed ownership reform of liquor enterprises in the province (Zhao, 2016).

\section{Liquors City Are Yibin}

A drunken city. The city's all send out a thick smell in the air. There are a lot of tourists to Yibin, independently of the first sentence. In fact, as long as you are willing, you stop in Yibin associated with liquor: Every moment from Jiangbei highway, you will see a huge liquor bottles stand in the middle of the road, to show you the ancient history of Yibin liquor; travel all the way from overseas to come over, and you are tired, of course, you can stay with the city of liquor, a hot bath, a good night's sleep; rest if you feel time is enough, you can go to see the small north street ChengDiao "drunk", Sanjiang road sculpture art gallery of the development of liquor; if you don't feel satisfied, you can also go to the Jiudu theater to enjoy a theatrical performance.

\section{Yibin Liquor Culture to the World}

With the passage of time, it cannot take away the faint smell of liquor; the Yibin people are gathering momentum and writing a new magnificent chapter in the accumulated history.

When Deng Xiaoping visited the United States in 1980, he presented his beloved wuliangye as a gift. This liquor, like nectar and jade, as the messenger of friendship, has brought the deep feeling of the Chinese people. On December 17, 1992, former Russian President Boris Yeltsin paid his first official goodwill visit to China. After the signing of the friendship agreement between the two sides, then-president Yang Shangkun held a state banquet in Diaoyutai State guesthouse and treated President Yeltsin and his party with wuliangye. Yeltsin repeatedly praised wuliangye as a real good liquor. In 2001, when President Jiang Zemin hosted a banquet for economic leaders attending the Asia-Pacific Economic Cooperation (APEC) economic leaders' meeting, wuliangye was placed on the main table and won praise from guests from all over the world. In early 2007, wuliangye, as a representative of the selected by the ministry of commerce the only food for Chinese brands in the "Sino-Russian cultural China year" activities, the same success, and this time their "international language", is the Chinese culture with the wuliangye systematic combination, full displaying the special role of liquor in Chinese society. In addition to wuliangye, Yibin's second-tier liquor brands also began to emerge in foreign countries, and were accepted and recognized by the world. In 1994, the grand opera of Syria won the gold 
award of the fifth Asia-Pacific international exposition. On October 22, 2009, Yibin hongloumeng liquor group, at the invitation of the organizing committee of "the 64th Anniversary of the United Nations and the 61st Anniversary of the UN Peacekeeping Mission" and "2009 US-China Investment and Cooperation BBS" celebration activities, entered the United Nations gate with a famous Chinese cultural liquor-hongloumeng liquor, which was designated as an official liquor by the United Nations. On May 12, 2009, held in Seoul, South Korea, the 27th Session of the International Food Festival, Yibin a dream of red mansions liquor group exhibition of various products with unique appearance, good taste, the classical Chinese culture essence of a dream of red mansions cleverly combined with culture and liquor culture, won the favour of many overseas businesses. The Chinese embassy in Japan, South Korea officials, Korea cultural exchange association director, South Korea's small and medium-sized enterprise research institute experts on a dream of red mansions booth, liquor tasting, know a dream of red mansions culture.

Korea and steamed dew group director Piao Rongqin line in Yibin city, understand the Yibin liquor history and culture, how to sell liquor products, etc., and during the next symposium held friendly exchanges with a dream of red mansions liquor group. On December 18, a wonderful "liquor feasts" event is looking forward to your attention. On the street, You may stop to enjoy "drunk liquor of Yibin sweet world liquor culture" theme tour, domestic famous liquor enterprise and the United States, France, Italy and so on more than 60 well-known liquor companies in more than 20 countries, more than 1,000 brand exhibition. In the wuliangye factory area of the 10-mile liquor city, you can watch the sacred liquor sacrificial ceremony full of mysterious color, and in the cultural relic flow cup pool, you can share the liquor with scholars and poets...

Yibin wuliangye, on the basis of doing a good job in the core industry, namely liquor industry, will focus on the development of four pillar industries, namely modern machinery manufacturing, polymer materials, photoelectric glass, and modern logistics industry. At present, the company has become the country's largest handicraft bottle production base. Wuliangye has established cooperative relationships with more than 100 well-known liquor companies at home and abroad, and signed strategic cooperation agreements with global spirits giant Diageo, according to a person in charge of the company's global subsidiary. We have been inundated with orders, so we can only take on more and dropping less. The average annual growth rate is above 40 percent (Tangjiu.com, 2016).

\section{Conclusion}

Yibin liquor culture is an important part of Chinese national culture. Yibin liquor is famous abroad for many famous brands. The culture of the mean of wuliangye liquor, the Zhuangzi culture of Jintan Yuye liquor, the soft and elegant culture of Shufu liquor, the culture of realizing one's dream, the culture of Chinese spring liquor, the culture of bamboo liquor, and the culture of Jinnanfu liquor all bring spiritual enjoyment to consumers. To accelerate the international communication of Sichuan liquor culture and create a unique brand of Sichuan liquor culture will help improve the international marketing ability of Sichuan liquor, expand international economic and trade cooperation, and promote the healthy development of Sichuan liquor industry. Let the world better understand Chinese liquor culture and promote the development of national cultural strategy and economic construction. 


\section{References}

Liang, L. J. (2014). New mode of Sichuan wine culture communication system under the background of pan-media. Youth and Society, 12, 305.

Liu, W. M. (2017). Structural imbalance and optimization of Chinese wine culture. Journal of Sichuan University of Science and Technology, 32(1), 26-36.

Sichuan wine has formed the development model of the whole industrial chain. (2016). Tangjiu.com. Retrieved from http://news.tangjiu.com/html/fenxibaogao/zhuantibaodao/2016/0601/222087.html

Zhao, S. Y. (2016). To vigorously promote supply-side reform and promote the jump to a high level of supply and demand balance. Retrieved from http://www.sc.xinhuanet.com/topic/2016qglh/ft/ft_zsy.htm

Zhong, J. M., \& Yun, H. (2017). Cultural interpretation of "wine” network. Journal of Sichuan University of Science and Technology, 2, 44. 